\title{
POLÍTICAS CURRICULARES NA FORMAÇÃO MÉDICA: APROXIMAÇÕES E DISTANCIAMENTOS ENTRE BRASIL E PORTUGAL
}

\author{
CURRICULAR POLICIES IN MEDICAL EDUCATION: SIMILARITIES AND DIFFERENCES BETWEEN BRAZIL \\ AND PORTUGAL
}

\author{
POLÍTICAS CURRICULARES EN LA FORMACIÓN MÉDICA: APROXIMACIONES Y DISTANCIAMIENTOS \\ ENTRE BRASIL Y PORTUGAL
}

\author{
Antonio da Silva Menezes Junior ${ }^{1}$ \\ Iria Bzrezinski ${ }^{2}$
}

Resumo Este artigo trata de uma pesquisa qualitativa sobre as práticas e políticas curriculares relacionadas à formação médica. O método adotado foi o materialismo histórico dialético, num estudo comparado de dois casos. A amostra foi intencional, com recorte em dois cursos de Medicina: o da Pontifícia Universidade Católica de Goiás (Brasil) e o da Faculdade de Ciências da Saúde, da Universidade da Beira do Interior (Portugal). O objetivo geral era comparar as políticas curriculares para o ensino médico nos dois países e analisar as práticas de organização curricular vigentes nas duas instituições tendo em vista as políticas de cada país. Filosoficamente, a pesquisa se fundamentou na teoria do agir comunicativo de Habermas. As aproximações entre os dois cursos perseveram na matriz curricular com o ensino-aprendizagem centrado no aluno e no perfil do egresso. Os maiores distanciamentos se evidenciaram na proposta de inserção social, preconizada pela Pontifícia Universidade Católica de Goiás, e no pressuposto da pesquisa e internacionalização da Faculdade de Ciências da Saúde, da Universidade da Beira do Interior. Concluiu-se que há necessidade de solidificação dos projetos pedagógicos atuais e de adoção de uma escola reflexiva com propostas reais, no sentido de vislumbrar a possibilidade de transformações sociais na realidade concreta.

Palavras-chave educação médica; currículo; saúde, políticas curriculares e agir comunicativo.
Abstract This article is a qualitative survey of curricular practices and policies related to medical training. The method used was dialectical historical materialism based on a comparative study of two cases. The sample was intentional, making a cross section of two medical schools: the Catholic University of Goiás (Brazil) and the College of Health Sciences of the University of Beira Interior (Portugal). The overall goal was to compare the curricular policies for medical education in both countries and to analyze the curriculum organization practices prevailing in the two institutions with a view of each country's policies. Philosophically, the study was based on Habermas' theory of communicative action. The similarities between the two courses remain in the curricular matrix, with teaching-learning focused on the student and on the graduate's profile. The greatest differences appeared in the social inclusion proposal advocated by the Catholic University of Goiás, and in the assumption of research and internationalization of the College of Health Sciences of the University of Beira Interior. It was concluded that there is a need to solidify the current educational projects and to adopt a reflective school with real proposals aiming to gain a glimpse into the possibility of social change in concrete reality.

Keywords medical education; curriculum; health, curriculum policies and communicative action. 


\section{Introdução}

A possibilidade de atuar na educação, hoje, significa, para aqueles que assumem a docência nos cursos de Medicina, a revisão de conceitos, conhecendo introspectivamente os seus valores. Implica que o profissional esteja aberto às mudanças a fim de se tornar o mediador, o facilitador de um processo de ensinagem, que poderá provocar transformações na formação de futuros profissionais na área de saúde.

Pretende-se contribuir, com este artigo, para o alcance das mudanças mencionadas, com uma visão de mundo, de homem e mulher, de educação, de universidade, de formação de formadores e de currículo como uma prática pedagógica, consistentemente fundamentada na epistemologia da educação e da saúde. Assim, faz-se indispensável a adesão à dialética, a fim de colocar em ação um modus operandi no contexto sociopolítico, cultural e econômico em que se articule a educação ao campo da saúde.

Por isso, acredita-se na necessidade de alcançar por meio da convivência e com a compreensão das duas áreas de atuação profissional um nível de "consciência política" (Freire, 1999) que permita o sujeito ser professor e médico crítico, de modo a redimensionar a práxis em favor da vida. Destaca-se que essa abordagem epistemológica é percebida na proposta de educação médica da Pontifícia Universidade Católica de Goiás (PUC Goiás), uma das instituições objeto do estudo comparado.

A escolha das duas instituições - PUC Goiás e Faculdade de Ciências da Saúde, da Universidade da Beira do Interior (FCS/UBI) - deu-se em virtude de vínculos profissionais, no Departamento de Medicina da PUC Goiás, e acadêmicos, com a UBI, e não por serem típicas ou estatisticamente representativas. Isso porque esses requisitos não se aplicam em pesquisa de natureza qualitativa, pois a investigação é "essencialmente analítica" (Ehrensperger, 2009, p. 76).

A PUC Goiás é uma instituição comunitária e comprometida com o desenvolvimento local e regional. Ao mesmo tempo, mantém a tradição inerente ao fato de ser a primeira universidade do Centro-Oeste brasileiro. É uma universidade contemporânea aliada à face da inovação e do dinamismo em busca de práticas formadoras que visem, em todos os seus cursos, à qualidade social e à "formação omnilateral" (Manacorda, 2007) de seus egressos.

O curso de Medicina foi autorizado pelo Ministério da Educação e Cultura (MEC) em 2005 e sua primeira turma graduou-se em agosto de 2011. São seis anos de formação na graduação e de dois a quatro anos de residência médica.

Sua congregação, referendada nas orientações das Diretrizes Curriculares Nacionais (DCNs) do Curso de Graduação em Medicina, conforme a resolução CNE/CES n. 4, de 7 de novembro de 2001 (Brasil, 2001), adotou uma metodologia de ensino com ênfase na problematização de situações 
sociais vividas pelos alunos na comunidade goiana e a busca de solução para elas. Trata-se de uma organização curricular e de práticas pedagógicas que se pretendem inovadoras e que são assumidas pelo corpo docente, comprometido com o enfrentamento de temáticas desafiadoras e que se propõe a aprofundar estudos a respeito das diretrizes curriculares dos cursos de ensino superior, decorrentes da implantação das reformas provocadas pela Lei de Diretrizes e Bases da Educação Nacional - LDB (Brasil, 1996). Esse aprofundamento de estudos também tem como foco a política curricular de formação médica na PUC Goiás e FCS/UBI.

No tocante ao curso de Medicina da FCS/UBI, sua criação foi estimulada pela aprovação governamental para a instalação de duas faculdades de Medicina no país, com a finalidade de dar um salto qualitativo no desenvolvimento de recursos humanos nos domínios da saúde. A exigência fundamental para que as universidades portuguesas fizessem sua candidatura era a apresentação pelos interessados de projetos inovadores que apresentassem alterações profundas no currículo médico e no ensino da Medicina em Portugal (Universidade da Beira do Interior, 2008). A proposta da FCS/UBI teve bom acolhimento e seu projeto de curso de Medicina foi aprovado, segundo resolução do Conselho de Ministros n. 140, de 4 de dezembro 1988.

As políticas curriculares do curso de Medicina estimulam a realização da análise da organização curricular e de sua dinâmica, por meio da qual se desenvolve a metodologia de ensino com ênfase na problematização de situações sociais vividas pelos alunos na comunidade goiana e portuguesa.

O objetivo geral foi a realização de um estudo comparado entre os contextos históricos, econômicos, culturais e educacionais do Brasil e de Portugal - particularmente do curso do Departamento de Medicina da PUC Goiás e do curso da FCS/UBI, para verificar como se efetiva a formação do médico, na década de 2000, à luz das mudanças na organização do curso de Medicina provocadas pelos novos parâmetros das diretrizes curriculares. Quanto aos objetivos específicos, pretendeu-se: estabelecer comparações entre as orientações curriculares decorrentes das DCNs do Curso de Medicina (Brasil, 2001) no Brasil e as advindas do Processo de Bolonha adotadas pelo curso de Medicina da FCS/UBI; e analisar as práticas pedagógicas instigadas pela metodologia de ensino que toma por base a problematização e solução de problemas, mediante um trabalho interdisciplinar, docente e discente. Sobre o Processo de Bolonha, Reinalda (2006) analisa

(...) o processo de Bolonha como uma tentativa de harmonizar Ensino Superior da Europa no contexto da concorrência global. Ele inclui material original de intergovernamentais e organizações não governamentais, até a reunião ministerial de Bergen do Processo de Bolonha em maio de 2005. A decisão política de criar uma área de Ensino Superior Europeu tem por objetivo reforçar a mobilidade entre as 
universidades europeias. O Processo de Bolonha começou em 1999 com a Declaração de Bolonha. Agora, há reuniões ministeriais regulares envolvendo quase todos os países europeus, membros da UE e de países terceiros. O livro não se restringe unicamente à Europa. Ele examina a evolução da Ásia e das políticas do Pacífico e do Ensino Superior por organismos globais, como a Unesco, o Banco Mundial (para a divisão Norte-Sul), e a OMC, onde alguns serviços de ensino superior são cobertos pelo Acordo Geral sobre o Comércio de serviços (Reinalda, 2006, p. 12). ${ }^{3}$

Tendo em vista o alcance desses objetivos, os eixos principais do referencial teórico são: as DCNs para os cursos de Medicina do Brasil, decorrentes da implementação das reformas curriculares do ensino superior, fundamentadas na LDB (Brasil, 1996); as habilitações acadêmicas advindas das orientações da Teoria do Agir Comunicativo de Habermas nas relações médico-paciente e docente-discente; e do Processo de Bolonha.

\section{A pesquisa em movimento: o referencial teórico}

Em uma rápida síntese do referencial teórico, é importante declarar que talvez o maior desafio do pensamento habermasiano para a educação, hoje em dia, seja o de compreender o processo educativo como formação do indivíduo em que a construção da identidade pessoal, em simultaneidade com a edificação do projeto da vida, é processo constitutivo do sujeito/indivíduo insubstituível.

A constituição de um ser humano como indivíduo e cidadão, conforme ensinamentos de Habermas (2002), concentra-se no desenvolvimento da competência comunicativa, necessária para o agir comunicativo. Este agir é entendido pelo autor como mecanismo responsável tanto para a reprodução, pelo indivíduo, de tradições culturais, de formas de conhecimento, de normas morais, quanto de sua transformação em cidadão, como sujeito enredado na teia das relações sociais.

Habermas (2002, p. 67) afirma que “o pensamento filosófico se originou na reflexão sobre a razão encarnada na cognição, fala e ação; e a razão permanece sendo o tema básico". Não seria uma surpresa, então, descobrir que o conceito de racionalidade é o fio condutor para sua análise sobre os processos de aprendizagem.

Outra característica marcante do pensamento de Habermas é sua defesa do 'projeto da modernidade', diante das críticas feitas pelos pensadores pós-modernos. Por mais que a modernidade tenha trazido problemas para a humanidade, Habermas (2002, p. 45), com apoio em Weber (1986, p. 78), tenta identificar "o processo da racionalização da sociedade moderna" como um potencial para a emancipação humana. O autor insiste na ideia da necessidade 
de completar esse projeto sem abrir mão do que já se conseguiu. Essa completude, no entanto, não poderá respaldar-se somente na racionalidade instrumental de técnicas do conhecimento, mas também na liberdade subjetiva, na autonomia ética, na autorrealização, no direito igualitário de participação, na formação de uma vontade política e no 'processo formativo' que se tornou reflexivo.

Segundo Fridman (1999), a investigação da nova ordem ainda está em seu início. Na contemporaneidade, diante das configurações institucionais, os autores dividem-se inclusive entre aqueles que conectam os artifícios em curso às forças abrolhadas com a industrialização e a urbanização e os que optam prefigurar uma ordem distinta daquela ressaltada no capitalismo industrial. Fridman (1999, p. 158) afirma que

O marxista americano Fredric Jameson, por exemplo, elaborador incansável do conceito de pós-modernismo, chega a defini-lo como uma revolução cultural no âmbito do próprio modo de produção capitalista nesse tempo de 'especialização flexível' na produção das mercadorias, da fragmentação das narrativas e do estilhaçamento do sujeito (Fridman, 1999, p. 158).

A analise habermasiana adota uma direção diversa, ao salientar o 'déficit' da racionalidade expandida na modernidade. Assim, tais divergências aparecem nos esforços de elucidação dos meios e modos em que se processa a vida atual com a globalização, a comunicação imediata, a volatilidade do capital, a ação à distância e a predominância da mídia na composição do universo simbólico das grandes massas.

É notório que as ideias do fim da história ou de uma ordem pós-moderna - que operam, na expressão de Habermas, uma provável despedida da modernidade - condenam o sentido de unidade da história, com aparentes implicações sobre a caracterização da sociedade atual. Nada obstante, pode-se ainda aguçar ou diluir a continuidade de forças despertadas no capitalismo clássico e na segunda revolução industrial com conjunturas presentes, mas torna-se imprescindível reivindicar o esclarecimento dos mecanismos e instituições que presidem as sociedades contemporâneas. Restaura-se o ânimo de estabelecer os sujeitos que vivem esse mundo (Mundo da Vida e Social) para além da atordoante imagem de Zygmunt Bauman do "inválido crônico que acompanha a vida da janela de um hospital" (Bauman, 1998, p. 194), assombração que persiste a impacientar.

Essas teses convidam ao aprofundamento na direção de uma teoria geral, todavia apenas evidenciam-se diferentes frentes de discussões, com a finalidade de promover contribuições teóricas que se alimentam mutuamente na tentativa de compreensão das novas dinâmicas. É o caso das teorias da oposição entre subjetividade e racionalização de Alain Touraine (1994), 
da reflexividade própria da modernidade avançada de Anthony Giddens (1996) e das tensões entre a ordem e a liberdade quando a constituição da identidade navega na fluidez de laços, segundo o pensamento de Zygmunt Bauman. São autores que rejeitam princípios totalizadores para a concepção da sociedade e, na crítica, às supostas leis fundamentais de seu desenvolvimento, procuram estabelecer o mal-estar contemporâneo.

\section{A pesquisa em movimento: método e percurso metodológico}

O método que orientou a pesquisa4 que deu origem a este artigo foi o materialismo histórico dialético. A seguir, far-se-ão algumas considerações importantes sobre a adoção desse método no estudo de casos.

A explicação e a compreensão da realidade social são feitas segundo referenciais teóricos que correspondem às visões de mundo que coexistem na sociedade. O processo saúde-doença, por exemplo, como manifestação do mundo social, não escapa a esse processo de interpretação.

Para utilizar um referencial filosófico dialético como marco teórico de interpretação, é preciso entendê-lo como teoria do conhecimento, que, a partir de determinada visão de mundo, tem como meta não só interpretar, como transformar a realidade, dado que esta corrente filosófica reconhece o papel político do ser humano como agente social de transformação da realidade, e não como mero receptor de determinações, dentre outras, culturais, econômicas e ideológicas.

Na contextualização da formação médica, nesse estudo, visando ao início do exercício da profissão, deu-se destaque para a categoria trabalho, uma vez que interessa à formação do indivíduo para o mundo do trabalho. Desta forma, fez-se necessário recorrer a Marx (1983), para a compreensão de dois conceitos fundamentais: o trabalho como "condição universal do metabolismo entre o homem e a natureza" e a "utilização da força de trabalho é o próprio trabalho" (Marx, 1983, p.149).

A importância da categoria trabalho, neste caso, no qual professores e aprendentes caminham juntos na formação de sujeito de forma integral, como cidadão-médico, pode ser expressa pelo seguinte questionamento, advindo de Freitas (1995):

Como os aprendentes se apropriam dos princípios teóricos e metodológicos que permitem a compreensão de sua prática pedagógica, da função social de seu trabalho, de seu projeto histórico? (Freitas, 1995, p. 44).

Aparece, então, a partir da dialética entre teoria e prática, a práxis que sofre 'ideologicamente' influências das ciências e da tecnologia. 
Segundo Habermas (2002), ao alocar a ciência como extraordinária atividade dotada de sentido e o ideal do método científico como caminho acautelado para o exato saber, o cientificismo desqualifica os demais campos do conhecimento e assume como sem sentido toda a forma de agir e de pensar que não possa ser identificada como técnica. Deste modo, a luta das ciências críticas com pretensão de libertação deve ser contra a realidade atual, que se caracteriza pela predominância da racionalidade técnico-científica, em que o cientificismo se apresenta como a manifestação mais acabada da moderna ideologia do capitalismo tardio.

A crítica deve lançar-se contra essa ideologia reducionista da racionalidade humana através da destruição da ilusão objetivista, mostrando que toda experiência científica, ou a 'ciência', pode ser, portanto, detectada e reconstruída por sujeitos que argumentam e procuram apresentar boas razões para a apreciação de suas vivências, dos seus saberes e do seu agir moral.

Portanto, no que diz respeito à metodologia, desenvolveu-se uma pesquisa qualitativa, com estudo de dois casos e de estudos comparados relativos às diretrizes curriculares e ao projeto político-pedagógico de dois cursos de Medicina. A amostra foi intencional, com recorte nos cursos de Medicina da PUC Goiás e da FCS/UBI.

A seleção dos casos estudados foi feita por uma amostra intencional que obedeceu a quatro critérios: relação com o objeto de pesquisa; facilidade de acesso aos projetos político-pedagógicos de dois cursos de Medicina; aproximações pedagógicas nas matrizes curriculares; e caráter comparativo da pesquisa.

A abordagem analítica ocorreu no primeiro momento, quando se estudou a formação médica e as políticas curriculares do ensino médico no Brasil e em Portugal. Neste ponto, buscou-se a contextualização e a caracterização dessas políticas.

Quando o interesse era o contexto específico - curso de Medicina da PUC Goiás e da UBI - o foco do trabalho voltou-se para o confronto das políticas curriculares adotadas nos dois contextos. Desta forma, pode-se afirmar que foi realizado um estudo comparativo. Para tanto, foi necessário, além da justaposição dessas realidades, a definição e a interpretação de fatos e contextos para, por fim, realizar a comparação entre os cursos de medicina das duas instituições.

O emprego da técnica de estudo de casos permitiu o aprofundamento do conhecimento da dinâmica curricular de cada projeto pedagógico investigado, enquanto a comparação possibilitou ressaltar a aproximação e o distanciamento entre esses projetos de formação do médico.

Foram analisados os projetos pedagógicos e as reformulações de ambos os cursos de Medicina. A análise dos documentos e a observação na UBI ocorreram em dois períodos distintos: em janeiro de 2011, durante um mês, e posteriormente, em janeiro de 2012, também durante um mês, com o intuito de 
restabelecer maior aproximação entre a organização e dinâmica curricular e a análise de documentos recentes da UBI. Na PUC Goiás, a observação foi direta e contínua, durante todo o desenvolvimento da pesquisa que durou três anos e seis meses.

\section{Aproximações e distanciamentos}

Com o propósito de se estabelecerem aproximações e distanciamentos entre as duas instituições formadoras, foi realizada a comparação entre os seguintes aspectos: pressupostos teórico-metodológicos; identidade do profissional; objetivos gerais e específicos; organização curricular; carga horária e duração; estrutura física; internato médico; concepções e processo de avaliação de desempenho de aluno; e inserção social.

\section{Curso de Medicina da PUC Goiás}

A trajetória da criação do curso de Medicina, pela PUC Goiás, foi marcada pela construção histórica, mediante amplas articulações acadêmicas, pedagógicas, técnicas e políticas.

É significativo relembrar que a primeira turma de médicos da PUC Goiás formou-se em agosto de 2011, após a submissão do projeto pedagógico do curso - PPC (Pontifícia Universidade Católica de Goiás, 2011) à avaliação por comissão do Instituto Nacional de Estudos e Pesquisas Educacionais Anísio Teixeira (Inep), do MEC (Inep/MEC), na qual obteve a nota máxima, 5. Em 2012, o curso já contava com três turmas de egressos.

A análise documental do PPC de Medicina de 2005, atualizado em 2011, revelou que o curso guarda reciprocidade com os fundamentos político-institucionais e religiosos da graduação da PUC Goiás, ao priorizar a excelência dos processos educativos e da formação humanística com base nas orientações da Igreja Católica.

Desde seu projeto inicial, a PUC Goiás assumiu pressupostos teóricos e metodológicos considerados inovadores: a adoção da metodologia de ensino sustentada na solução de problemas, na interdisciplinaridade dos componentes curriculares, na integração de conteúdos, no contato dos acadêmicos com a realidade do sistema de saúde desde o início do curso e no exercício da medicina em evidência.

A comissão de reformulação curricular do Departamento de Medicina, frente ao que já vinha ocorrendo na área assistencial e de gestão, chegou ao modelo proposto, baseado em atividades integradoras e conteúdos temáticos, organizados em sistemas e fases evolutivas. 
Na proposta curricular foi eliminada a separação entre ciclo básico e profissionalizante. Essas mudanças mantinham consonância com o disposto na LDB (Brasil, 1996) e nas bases contidas na resolução n. 4, do Conselho Nacional de Educação, aprovada em 7/11/2001, que instituiu as DCNs do Curso de Graduação em Medicina (Brasil, 2001; Pontifícia Universidade Católica de Goiás, 2011).

Conforme o atual PPC, o currículo deve ser centrado no interesse do estudante e, por essa razão, ser dinâmico, flexível e formativo. Com tais características, o currículo do curso de Medicina da PUC Goiás mantém-se em processo contínuo de avaliação, discussão, reflexão e reformulação.

Os princípios, o referencial teórico, as DCNs do curso de Medicina e as exigências do mundo do trabalho consistem nos fundamentos epistemológicos, científicos e pedagógicos que referendam o traçado do objetivo geral do curso de Medicina da PUC Goiás, nos seguintes termos:

Formar médicos e médicas com ampla base epistemológica, competentes no atendimento e no gerenciamento da saúde individual e/ou coletiva, em sintonia com as políticas de saúde vigentes e capazes de uma visão integrada, ética e humanizada do processo saúde-doença (Pontifícia Universidade Católica de Goiás, 2011, p. 7).

Como se observa, são as diretrizes, os princípios, os fundamentos teóricos e metodológicos e as relações objetivas com o mundo do trabalho que deixam transparecer os indícios do perfil profissional do médico, como sujeito de sua formação na PUC Goiás, mediada pelos médicos formadores de médicos.

Com efeito, é possível vislumbrar um profissional cidadão-médico que reivindica a responsabilidade e o compromisso com a sociedade contemporânea, o que implica conhecimento profundo de sua área de saber, associado à postura ética, humanizadora e crítica nas relações profissionais, como se verifica no perfil do egresso enunciado no PPC de Medicina da PUC Goiás:

Formação generalista, humanista, crítica e reflexiva. Capacitado a atuar, pautado em princípios éticos, no processo de saúde-doença em seus diferentes níveis de atenção, com ações de promoção, prevenção, recuperação e reabilitação da saúde, na perspectiva da integralidade da assistência, com senso de responsabilidade social e compromisso com a cidadania, como promotor da saúde integral do ser humano (Pontifícia Universidade Católica de Goiás, 2011, p. 7).

Está prevista, ainda, como habilidade a ser desenvolvida pelos acadêmicos: a visão global do ser humano. Esta visão encontra ressonância nas relações humanas, vividas, na contemporaneidade, com base na Teoria do Agir Comunicativo de Habermas (1987), que supõe a inclusão do outro. A propositura habermasiana visa a (des)transcendentalizar a razão pela intersubjetividade 
e a leitura do 'Mundo da Vida' e do mundo social, na busca do entendimento ou do consenso, mesmo que este seja a mera convicção da possibilidade do dissenso.

Desta forma, destaca-se que não basta propor a formação de um médico cuja razão e leitura do mundo do outro utilize ideologicamente qualquer argumento para impor seu conhecimento pela diferença de posição, a fim de manipular e obter a submissão de seus doentes ou familiares. Tornar-se um médico crítico e aberto à inclusão do outro por meio do diálogo implica proporcionar ao paciente a capacidade de, nesta busca de entendimento, ter voz participante.

No que diz respeito à organização curricular, é evidente no PPC a intencionalidade de superar o paradigma tradicional da formação médica fragmentada, que, por sua vez, gera a visão restrita e segmentada que o médico constrói sobre o paciente. Teoricamente, a organização curricular em ciclos de desenvolvimento da aprendizagem, agrupados em módulos, é entendida pelos elaboradores do PPC como mecanismo que, na prática, deverá ultrapassar a estruturação disciplinar.

São oferecidos aos alunos conteúdos teóricos complementares para sua formação geral. O desenvolvimento curricular propõe a articulação teoria e prática mediante casos motivadores, grandes temas, ou temas abrangentes, e nas atividades práticas (Pontifícia Universidade Católica de Goiás, 2011). Neste aspecto, a valorização das interações cotidianas permite, principalmente em ambientes de maior inserção social, o convívio com a realidade concreta, instigando no aprendente o exercício da competência comunicativa.

Ainda no que concerne ao desenvolvimento e à dinâmica curricular, o projeto pedagógico abaliza as unidades na composição dos módulos como uma das formas de integração das unidades. Essas são propostas para substituir as disciplinas do modelo curricular tradicional, reconhecido por trabalhar com disciplina, ou, conforme Zabalza (2004), centrado na disciplina e aprendizagem formal.

A análise curricular, portanto, permitiu a identificação no PPC de Medicina da PUC Goiás o que Pacheco (2001) considera como o currículo real, que se situa em um contexto de ensino e que corresponde ao currículo operacional. "Trata-se, portanto, do currículo que acontece na prática diária da escola" (Pacheco, 2001, p. 69-70).

No PPC é descrita, em detalhes, a metodologia de ensino-aprendizagem, baseada em problemas, que requer o desenvolvimento em semestres organizados em ciclos com módulos estruturados em unidades, e estas em conteúdos temáticos (Pontifícia Universidade Católica de Goiás, 2011, p. 19).

A dinâmica curricular preconizada, em que as disciplinas do modelo tradicional são organizadas em ciclos, e destes em módulos, dispõe-se a oportunizar melhores condições de integração de conteúdos específicos e 
a articulação metodológica. Esse modelo, aliado aos pressupostos já explicitados, com suas consequências em relação às metodologias de ensinagem, suscitaria a formação omnilateral (Manacorda, 2007) do futuro médico. Esta forma de organização curricular pretende representar o diferencial em relação ao modelo curricular tradicional, haja vista que o estudante, com a mediação do professor, poderá edificar o conteúdo, da parte para o todo e vice-versa, diante da abrangência e complexidade do conhecimento a ser estudado e apreendido.

Outro aspecto abordado é a carga horária e duração do curso. O currículo de 2011 teve uma variação em relação ao projeto pedagógico de 2005, ou seja,

(...) a proposta original de 8.040 horas (536 créditos), sendo 4.920 horas (328 créditos) teóricas práticas e 3.120 horas (208 créditos) de internato, foi modificada para 8.160 horas ( 544 créditos), sendo 5.190 horas (346 créditos) teóricas práticas e 2.970 horas (198 créditos) do internato com 500 horas de atividades extracurriculares (Pontifícia Universidade Católica de Goiás, 2011, p.18).

Em ambas versões, a carga horária é condizente com as DCNs, com tempo adequado de dedicação ao internato, que corrobora com a proposta de permitir, no transcorrer da práxis, a transformação do profissional em médico cidadão e autônomo.

Em face disso, as práticas pedagógicas devem contemplar a interdisciplinaridade de forma ampla e dinâmica, construtiva e objetiva, por meio de metodologias nas quais os discentes, a partir de determinado contexto, são levados a identificar problemas e a apontar soluções, resultantes da reflexão crítica acerca dos casos apresentados. “O educador será o facilitador e mediador deste processo" (Pontifícia Universidade Católica de Goiás, 2011, p. 9).

Na busca da coesão entre duas propostas metodológicas diferentes, mas que ao mesmo tempo fogem do padrão tradicional e obedecem às metodologias preconizadas pelas DCNs do Curso de Medicina (2011), a PUC Goiás utiliza a Aprendizagem baseada em problemas e a Problematização como os eixos basilares que interagem de forma interdisciplinar com uma proposta de transdisciplinaridade.

Um dos aspectos que contribuem fundamentalmente para o alcance dos objetivos do curso é a inserção social do aprendente, desde o início do curso, de modo permanente e contínuo, ao longo dos seis anos de formação do futuro médico. Destaca-se que a organização curricular assumida pelo PPC pautou-se pelas orientações das DCNs do Curso de Medicina, não se descuidando das especificidades regionais e do contexto em que o curso se insere, qual seja, uma universidade comunitária.

Outro aspecto contemplado no PPC é a formação científica, que se potencializa com a incorporação das vivências decorrentes da inserção social 
do alunado na realidade concreta da prática da medicina e o compromisso comunitário. O paradigma da formação é balizado pela competência profissional no exercício da medicina com domínio de conhecimentos e de habilidades, com atitudes éticas na relação médico-paciente.

Merece destaque o que intenta o desenvolvimento do PPC ao defender uma política de regionalização da medicina no estado de Goiás, sustentada na análise da conjuntura social e econômica pelos estudantes, assim como a inserção de profissionais para atender à comunidade em suas reais necessidades, que vão desde a vigilância à promoção e à atenção primária à saúde até os níveis de alta complexidade.

Comprova-se, desta forma, a urgência na formação médica que possibilite a atuação de médicos com o perfil profissional concebido pelo curso de Medicina da PUC Goiás, na medida em que os dados nacionais (Datasus, 2012) informam que os 7.631 agentes comunitários de saúde correspondem a uma cobertura de apenas 62,9\%, e que as 1.049 equipes da Estratégia Saúde da Família atuam em 56,9\% da população goiana.

Em 2012, Goiás contava com 478 hospitais públicos credenciados ou contratados, 25 maternidades e em torno de 12.500 médicos em exercício, para assistir, aproximadamente, seis milhões de habitantes. Destes, 78,12\% estão concentrados na capital do estado (Datasus, 2012).

Os espaços práticos do processo ensino-aprendizagem tiveram a oportunidade de sinalizar demandas sociais e expectativas pela presença da instituição de ensino superior, utilizando encontros legalmente constituídos, tais como: Conselho Municipal de Saúde, Conselho Local de Saúde da Vila Mutirão, reunião com os gestores do Distrito Escola, Fórum do Distrito Sanitário Noroeste de Goiânia, reunião com as equipes da ESF, usuários e líderes da comunidade, dentre outros. No que diz respeito à pesquisa e à produção científica:

Vale ressaltar que, durante três semestres do Internato, os acadêmicos desenvolvem o Trabalho de Conclusão de Curso (TCC). O TCC é uma exigência curricular para a conclusão do curso e deve ser entendido como um momento de síntese e expressão da totalidade da formação do profissional, concretizando as competências, habilidades e atitudes específicas referentes ao conhecimento dos métodos e técnicas de investigação e elaboração de trabalhos acadêmicos e científicos. O TCC também gera produção científica, já que o acadêmico tem que projetar e desenvolver uma pesquisa abordando um tema específico de relevância social e científica e que, no final, deve produzir um artigo que deverá ser enviado para publicação. Os trabalhos realizados no TCC são de natureza quantitativa e qualitativa, clínica ou experimental (Pontifícia Universidade Católica de Goiás, 2011, p. 20).

A vivência das orientações constantes das DCNs do curso de Medicina e a consequente percepção das reais necessidades da população favoreceram 
o desenvolvimento de uma rede social e comunitária de respeito e aceitação mútua pela presença da graduação, extensão, pesquisa e pós-graduação, na busca crescente de aprimoramento profissional, técnico, humano, ético e de inserção social.

As mudanças indispensáveis para a formação médica realizada pela PUC Goiás requerem dos docentes alterações em suas práticas pedagógicas, muitas vezes pautadas no processo de ensino-aprendizagem tradicional. Sob a égide dessa abordagem metodológica do processo de ensino,

a ênfase é dada às situações de sala de aula, onde os alunos são 'instruídos' e 'ensinados' pelo professor (...) subordina-se a educação à instrução, considerando a aprendizagem do aluno como um fim em si mesmo (Mizukami, 2007, p. 13).

Essa abordagem pode significar um obstáculo epistemológico (Bachelard, 2008) e requer estudos sobre a docência e uma formação específica que escape à simples racionalidade instrumental positivista. Entende-se, então, que é pertinente indagar: A organização e dinâmica curriculares do curso de Medicina da PUC Goiás traz inovações?

Um ancoradouro seguro que pode oferecer algumas alternativas é o referencial tecido em seus fundamentos teóricos e no modus operandi do trabalho docente, a ruptura com as formas tradicionais de ensinar e de aprender e a concepção de gestão participativa para a reconfiguração de conhecimentos e saberes. Esses elementos estão evidenciados tanto na descrição dos pressupostos teóricos e metodológicos quanto nas práticas pedagógicas constantes no PPC. A observação direta do pesquisador e a atuação profissional, durante diversos momentos da gestão curricular, permitiram confirmar essas evidências. No entanto, as práticas ainda não ultrapassaram a normatização, seguem normas e suscitam soluções particulares, não coletivas. Afirma-se que perduram as práticas conservadoras adaptadas às políticas educacionais vigentes.

A análise curricular remete a Roldão (1999), que esclarece: o sentido da lógica da administração nacional uniforme do currículo tende a ser sobreposta de forma crescente e frequente pela lógica de projeto curricular contextualizado. Este não prescinde da busca de uma gestão autônoma das escolas, justificada pela importância de maior eficácia e adaptação aos públicos, que passam por visíveis dinâmicas sociais (saúde, economia, apoio social, cultura, entre outras). No caso da educação médica, trata-se de

equacionar caminhos diferenciados dentro das balizas nacionalmente estabelecidas e controladas, que conduzam a um maior sucesso da escola na sua função essencial; conseguir que os alunos adquiram as aprendizagens curriculares com uma eficácia aceitável que lhes permita assegurar a sua sobrevivência social e 
pessoal e um nível de pertença e desempenho sociocultural que permita à sociedade manter-se equilibrada e superar os riscos de ruptura (Roldão, 1999, p. 29).

Nota-se, portanto, que a formação de um profissional médico de forma generalista e com a visão de totalidade dos contrários, nesta tentativa de mudança paradigmática, imperativamente com as mudanças contextuais frequentes, pode exprimir no movimento dialético o vislumbrar de uma sociedade transformadora.

\section{Curso de Medicina da FCS/UBI}

Como já descrito, o desenvolvimento de recursos humanos com domínio da saúde com qualidade motivou a criação do curso de Medicina da FCS/UBI (Faculdade de Ciências da Saúde, 2008), aprovado pela resolução do Conselho de Ministros n. 140/1998.

A tônica da proposta era o desenvolvimento de modelos inovadores de formação, pautados por padrões científicos, pedagógicos e assistenciais de elevada qualidade. Um dos requisitos para sua implementação era a articulação com as unidades de prestação de cuidados de saúde, o equivalente, no Brasil, ao Sistema Único de Saúde, mas com particularidades asseguradas por um modelo organizacional diferenciado das práticas de formação médica até então efetivadas.

Ao explicitarem os pressupostos do curso de Medicina, os elaboradores do projeto fazem forte crítica aos modelos tradicionalmente existentes. De acordo com a coordenação pedagógica do curso, os cursos tradicionais geralmente possuem planos de estudos compostos de disciplinas desarticuladas, com programas desenvolvidos pelos seus docentes e se caracterizam pela 'pulverização desintegrada', que contraria os processos de elaboração e construção do conhecimento de modo coletivo e interdisciplinar. Este modelo é considerado desmotivante, além de antieducativo, pois são ministradas aulas magistrais, ensino teórico e avaliação fundada na memorização (Cunha, 2006).

Entende-se que esse modelo tradicional de formação não atende às necessidades da educação médica na atualidade e precisa ser reformulado. Além disso, a nova proposta precisa ter sua implantação acompanhada para atender ao previsto que fora

devidamente concebido em sua finalidade, objetivos, organização, conteúdos programáticos, atividades, métodos pedagógicos, critérios e modos de avaliação da aprendizagem e do ensino, tomando com lucidez e firmeza as devidas precauções em ordem a que a realização exprima com fidelidade a concepção (Machado, 1991 apud Ehrensperger, 2009, p. 355). 
A análise do PPC da FCS/UBI evidenciou que a integração é um de seus pressupostos básicos. Este princípio implica coordenação e execução integrada do currículo, das quais se incumbe o conjunto dos docentes. O Mestrado Integrado em Medicina, por exemplo, surgiu de determinações do Processo de Bolonha com a mudança do ensino superior para a organização curricular em ciclos, por extenso, com dois ciclos: cursos com maior abrangência e maior carga horária, que passaram a integrar o Mestrado; e cursos aligeirados, de modo que o mestrando defende a dissertação no final do sexto ano no Mestrado Integrado em Medicina. No final do curso, o aluno deve ter adquirido um conjunto de aptidões que o habilitem à compreensão "dos conhecimentos, das atitudes e perícias" (Faculdade de Ciências da Saúde, 2008, p. 12).

O leque de objetivos propostos é abrangente. A análise desses objetivos revelou a busca pela FCS/UBI da construção de um perfil profissional 'generalista', com competências que vão além do domínio da técnica.

Habermas (2002) teoriza acerca da valorização da técnica pela técnica e da técnica como ideologia e ensina que importa recuperar e preservar, no espaço público da escola, a interatividade da razão comunicativa inscrita no Mundo da Vida para combater déficits racionais vigentes no paradigma pedagógico da modernidade. Deve-se formar cientistas e técnicos competentes, mas com outra 'alma', porque são médicos reflexivos e políticos capazes de conduzir competentemente a saúde pública, compromissados com a democracia e a inclusão do outro.

Os objetivos denotam que estimular a formação de atitudes é um processo que tem influência significativa no comportamento do futuro médico. Em conformidade com o PPC da FCS/UBI e as diretrizes indicadas pelo Processo de Bolonha, essa formação de atitudes é tão importante quanto a aquisição de conhecimentos técnicos e científicos. Essa é uma formação humana omnilateral (Manacorda, 2007) que se preocupa com o homem e a mulher como um todo - dialeticamente inseridos numa sociedade onde existem conflitos de classe, com hegemonia do conservador e da classe dominante. Trata-se da base fundamental do currículo integração, que se contrapõe ao currículo coleção de disciplinas.

Apple (2006) assinala que a responsabilidade, o desempenho de objetivos, o atendimento aos padrões, o uso de testes nacionais e os currículos padronizados são criados de tal forma que impedem qualquer mudança. Apesar de aparentarem simbolizar tendências diferentes, na verdade se fortalecem e ajudam a sustentar posições chamadas conservadoras do cotidiano. $\mathrm{O}$ autor enfatiza que na programação de objetivos a serem atingidos pelo curso de Medicina devem ser consideradas as necessidades de saúde das populações, as prioridades e os recursos do país, de tal forma que a universidade possa contribuir para a solução dessas necessidades, formando médicos com 
domínio de conhecimentos científicos atualizados e com uma formação humanista integral (Faculdade de Ciências da Saúde, 2008). Resulta desta relação a conexão com a realidade concreta, por meio do nexo entre a teoria e a prática (Habermas, 2007).

Ao analisar o critério avaliação, na organização e no planejamento curricular, é notório que o ato avaliativo está presente nos diferentes contextos e estágios do desenvolvimento curricular. A avaliação interna é destinada às suas próprias atividades, abrangendo o desempenho dos professores, o progresso de cada aluno, o funcionamento da turma, os processos e as práticas dos professores.

O modelo pedagógico adotado pela FCS/UBI mantém consonância com as recentes teorias de ensino e aprendizagem e foi proposto pelo Processo de Bolonha. Os fundamentos desta organização curricular baseiam-se na importância do contato imediato do estudante com problemas de saúde, como recomendado pela PUC Goiás e pela FCS/UBI, desde o início do curso. É na fase mais avançada do curso, entretanto, que alguns conhecimentos dos domínios científicos e culturais são mais considerados, pois negam a realidade em que, cada vez mais, os problemas são interdisciplinares e multidisciplinares. Neste sentido, é esclarecedora a posição de Ehrensperger (2009), citada por Machado (2002, p. 35), pois o homem “não é entendível por aproximações parciais sucessivas, mas por aprofundamentos sucessivos de uma abordagem sistematicamente global".

O curso de Medicina da FCS/UBI tem alta carga horária de atividades, havendo a preocupação para que os horários não fiquem saturados por atividades escolares formais, ao oportunizar espaços para atividades de estudo de livre escolha dos alunos.

A avaliação da aprendizagem, coerente com o modelo pedagógico, é contínua e busca o diagnóstico qualitativo do saber pensar, saber fazer e saber estar (Machado, 1991). De acordo com o PPC, deve haver dedicação com vistas a avaliar qualitativamente o desempenho dos alunos, numa avaliação formativa ou qualitativa (Pacheco, 2001)

A valorização, no que diz respeito às competências, e as atitudes, e em especial a capacidade de comunicação, exigem o entendimento de que o novo paradigma pedagógico comunicacional, cujo núcleo racional instaura-se apoiado na interatividade processual-discursiva do Mundo da Vida, precisa primar pela recuperação intersubjetivo-discursiva da formação científica, se quiser servir de modelo teórico para se repensar e pleitear a correção de dissonâncias patológicas herdadas na modernidade tardia.

Além da avaliação interna, a UBI implantou um processo de avaliação externa por meio da instauração de uma Comissão Externa de Avaliação que acompanha o curso de Medicina anualmente. Tal comissão é formada por especialistas nacionais e estrangeiros, especialistas em educação médica e 
representantes da Organização Mundial da Saúde. Essa avaliação externa se efetiva pelo contato com relatórios anuais, além de visita e observação in loco.

O processo avaliativo tem provocado diversas mudanças no curso, desde as referentes ao plano de estudos, como inclusão, supressão, agrupamento, ajustes de carga horária de áreas ou módulos, até aquelas indicativas de ajustes internos de conteúdos de módulos, de metodologias de trabalho, de avaliação e de introdução de temas, dentre outras. Estas mudanças são descritas nos relatórios anuais e praticadas no ano letivo seguinte.

Foi muito difícil a aceitação do curso por outras instituições de ensino na área médica, principalmente por aquelas orientadas por metodologias de ensino de 'escolas tradicionais'. Os docentes e gestores descreveram em relatórios as dificuldades enfrentadas no início, e que só recentemente tem sido reconhecida a excelência do curso de Medicina da FCS/UBI por instituições da área médica de Portugal. Os gestores acreditam que o desempenho dos egressos foi o aspecto que mais influenciou a aceitação pela comunidade médica do país.

A análise dos planos de estudos em 11 anos de funcionamento do curso de Medicina da FSC/UBI permitiu verificar que uma série de planos de estudos distintos foram implantados. O mais recente decorreu da adequação às exigências do Processo de Bolonha. Desde a criação do curso, os planos de estudos enfocam a estreita relação entre a pesquisa e a pós-graduação, que engloba um componente de investigação importante, decisivo no desenvolvimento de uma faculdade de ciências da saúde atual e inovadora.

O projeto do Mestrado Integrado em Medicina da UBI propõe modelos inovadores de formação, pautados por padrões científicos, pedagógicos e assistenciais de elevada qualidade, e que satisfazem aos requisitos adotados pelas instâncias nacionais, comunitárias e internacionais relevantes. Quanto à internacionalização, a FCS mantém protocolos com importantes instituições de ensino e de investigação no mundo. Dadas as amplas relações externas que o curso possui, bem como o seu reconhecimento nacional e internacional, seria de esperar maior intercâmbio de alunos estrangeiros e a presença de acadêmicos de outras universidades de Portugal. Ocorre que, exatamente em função do modelo diferenciado (ausência de disciplinas), não existem muitas facilidades para que a mobilidade ocorra com frequência.

No que tange ao Processo de Bolonha, os documentos apreciados mostram que o curso praticamente não foi afetado pelas novas políticas, haja vista que sua estruturação já mantinha conformidade com as recomendações pedagógicas propostas: modelo de aprendizagem centrado no aluno, avaliação contínua, objetivos de aprendizagem explícitos, orientação tutorial, dentre outros. As alterações introduzidas, devido ao Processo de Bolonha, foram concernentes aos ajustes do plano de estudos vigentes em 2004-2005, decorrentes das exigências de conversão de créditos e a criação do segundo ciclo, por meio do Mestrado Integrado. 
Faz-se necessário sublinhar as medidas adotadas por órgãos superiores da UBI em resposta às políticas curriculares de Portugal e da União Europeia, que se traduzem em adequações curriculares diante das demandas representadas pelo Processo de Bolonha que se materializam em normativas internas no que se refere a diversos aspectos, dentre os quais a oferta normativa, os processos de organização de currículos, as metodologias de ensino e os procedimentos de avaliação. Quanto às normativas, observou-se uma intermediação entre as políticas 'nacionais' - que, de fato, não são genuinamente nacionais, pois reproduzem o que está posto supranacionalmente - e a realidade concreta da FCS. A UBI foi uma das pioneiras no âmbito das universidades portuguesas a aderir ao Processo de Bolonha, criando uma regulamentação interna que tem facilitado esse movimento.

Sabendo-se da imperativa adequação do curso ao Processo de Bolonha, nacional e institucionalmente, os gestores encontraram um caminho de não rompimento e de ajuste sem desqualificar a trajetória percorrida. Além disso, em relação às práticas pedagógicas e de avaliação utilizadas, também se verifica um processo adaptativo. O que de fato aconteceu após a adequação ao Processo de Bolonha foi a maior centralidade dessas novas práticas no cotidiano do curso. Diante das análises realizadas, ficou evidente que as políticas e as ações curriculares precisam nutrir-se de uma visão clínica, a qual, de acordo com Pacheco (2001), deve focar nos movimentos singulares dos cenários socioeducacionais (Pacheco, 2001).

A seguir apresentam-se resultados da análise comparada entre os cursos de Medicina da PUC Goiás e o curso de medicina da FCS/UBI, na procura dos pontos de aproximação e de distanciamento.

\section{Aproximações e distanciamentos: uma análise comparada}

Os casos estudados inserem-se em contextos históricos, sociais, políticos e econômicos com características muito peculiares. Existem, contudo, algumas semelhanças e diferenças entre eles, e as mais evidentes são as aproximações e os distanciamentos, que podem ser assim enunciados:

a) No processo de formação do profissional, os cursos primam pela excelência. O egresso da FCS/UBI é médico generalista, com uma visão crítica de mundo, consciente da necessidade de permanecer na busca de conhecimento, habilidades e atitudes. Em consequência da adequação curricular, ocorrida a partir da inserção no Processo de Bolonha, o curso de medicina da UBI abrange dois ciclos, com um total de 240 créditos, e denomina-se Mestrado Integrado em Medicina. No tocante ao egresso da graduação da PUC Goiás, também é médico generalista, tem visão crítica e, ao atuar no mercado de tra- 
balho, se lança em busca do autoconhecimento inserido no sistema de saúde pública do país, e dá continuidade à formação na residência médica.

b) A metodologia de ensino, desenvolvida pelos dois cursos, obedece aos padrões normativos de cada contexto.

c) A carga horária e duração do curso, em termos numéricos, são semelhantes. A diferença é que na UBI o médico generalista fica no internato apenas no último ano (sexto), enquanto na PUC Goiás o aluno vai para o internato a partir do módulo IX, e lá permanece por quatro semestres, incluindo um mês de internato rural.

d) O processo de avaliação de ambos os cursos é formativo, condizente com o processo de aprendizagem. O que os diferencia é a acreditação. Na UBI, a acreditação é internacional, seja pelo próprio sistema europeu, seja pelos Estados Unidos, por meio da Harvard Medical School, enquanto na PUC Goiás a avaliação é contínua, com atividades integradoras, e a acreditação é feita pelo Inep/MEC e Sistema Nacional de Avaliação do Ensino Superior (Sinaes) por meio do Exame Nacional de Desempenho dos Estudantes (Enade).

e) A organização curricular segue modelos semelhantes: tanto o curso da UBI quanto o da PUC Goiás é organizado em blocos e unidades.

f) A gestão curricular do curso da UBI é feita pelo Gabinete de Educação Médica, responsável pela coordenação do currículo, da avaliação e das atividades extracurriculares. Os gestores são um diretor médico e o coordenador pedagógico. A administração é colegiada, pois a FCS tem um presidente e as decisões são compartilhadas com o Conselho Administrativo, ao passo que no curso da PUC Goiás a gestão é de responsabilidade do diretor médico, dos coordenadores pedagógicos e dos coordenadores de cada módulo. As decisões acadêmico-administrativas de relevância são tomadas em reuniões com o colegiado de professores.

g) A inserção social dos estudantes na UBI, durante o processo formativo, é feita por meio de convênios em hospitais que atendem a rede pública de saúde e há forte tendência para formar o médico pesquisador, enquanto os acadêmicos da PUC Goiás são inseridos na comunidade desde o primeiro módulo. Grande parte de sua aprendizagem ocorre no sistema de saúde pública, em nível primário, secundário e terciário (especialidades). O diferencial da PUC Goiás é o estímulo aos estudantes para a participação em atividades comunitárias, como na Semana de Cultura e Cidadania, promovida pela própria instituição anualmente, e por meio das ligas acadêmicas, que desenvolvem projetos no município de Goiânia, em seus arredores e no interior do estado de Goiás.

h) A internacionalização do curso de Medicina da UBI se efetiva por um programa de intercâmbio entre os países europeus - o Erasmus - e pelo desenvolvimento de atividades integradas com a Harvard Medical School, 
enquanto o curso da PUC Goiás inicia a prática de intercâmbios com universidades latino-americanas, europeias (Portugal e Espanha) e estadunidenses.

\section{Considerações finais}

A proposta do estudo era estabelecer comparações entre as orientações curriculares decorrentes das DCNs do curso de Medicina no Brasil, encampadas pela PUC Goiás, e as orientações advindas do Processo de Bolonha, adotadas no curso de Medicina da UBI, em Portugal.

Observou-se que, nos dois casos, foram utilizadas políticas curriculares que se tornaram fatores determinantes para a formação do profissional médico, com identidade diferente do modelo tradicional de ensino médico. Ambas as universidades, em seus projetos pedagógicos, propuseram a formação do médico generalista, com base em visão de totalidade do ser humano, orientando-se pelos aspectos biológico, psíquico e social.

No curso da FCS/UBI, o profissional egresso deve estar preparado para atender às demandas de mercado de trabalho, exigidas pelo contexto sócio-histórico e cultural em que vive. Tais exigências instigam o jovem a enfrentar a competitividade, com competência para o atendimento como do médico da família, mas também com preparo para o intercâmbio de experiências, principalmente no que diz respeito às pesquisas, haja vista que o título do egresso do curso de Medicina da UBI, em conformidade com o Processo de Bolonha, é conferido pelo Mestrado Integrado em Medicina.

No curso da PUC Goiás, o profissional é inserido precocemente no ciclo profissionalizante, atuando na comunidade, conhecendo com embasamento teórico as ações primárias do sistema público de saúde. O egresso do curso também é um profissional médico generalista, com visão biopsicossocial, com capacidade crítica e com forte inserção social. Os programas de extensão possibilitam trazer o conhecimento vivido junto aos serviços de saúde pública para serem discutidos, visando às alternativas de solução em âmbito acadêmico.

Outro propósito deste estudo foi analisar as práticas pedagógicas instigadas pela metodologia de ensino que toma por base a problematização e a solução de problemas, mediante trabalho docente e discente interdisciplinar. Destaca-se que as práticas pedagógicas estão correlacionadas com o perfil do egresso previsto tanto pelas DCNs do curso de Medicina no Brasil quanto pelas modificações ocorridas nos projetos pedagógicos para atender às solicitações do Processo de Bolonha em Portugal.

No curso de medicina da UBI, o currículo é centrado no aprendente, com a concepção de práxis, seguindo a orientação da ação-reflexão-ação e da ação comunicativa, o que proporciona a formação de um médico crítico, 
que busca a autonomia e a emancipação. Para dar suporte a esse currículo, a metodologia de ensino é a aprendizagem baseada em objetivos, com o curso dividido em blocos e unidades. O aluno permanece durante dois anos na formação básica; três anos na formação profissionalizante e, no último ano, no internato, quando defende a dissertação de mestrado. As pesquisas desenvolvidas no mestrado integrado fazem parte de acordos e parcerias com instituições internacionais.

No curso de Medicina da PUC Goiás, o currículo tem por base as concepções da teoria crítica referentes à práxis e à ação comunicativa. Procura atender às diretrizes nacionais que propõem a emancipação e a autonomia, baseadas em princípios ético-profissionais. Durante o curso, é utilizada a metodologia da aprendizagem baseada em problemas e, como outro eixo norteador do currículo, a problematização, cuja fundamentação epistemológica se relaciona com o paradigma de organização educacional comunitária, participativa e democrática.

Destaca-se, ainda, que ambos os cursos adotam matrizes curriculares orientadas pelas políticas nacionais do ensino superior para atender às exigências do mercado de trabalho.

Pelo exposto, conclui-se que o maior distanciamento entre os dois cursos reside no interesse de cada instituição em atender ao mercado de trabalho. Enquanto na UBI o profissional forma-se mestre em Medicina em seis anos, na PUC Goiás o profissional crítico e com visão emancipatória domina conhecimento, habilidades e atitudes para lidar com os problemas de saúde pública enfrentados no cotidiano. 
Resumen Este artículo trata de una investigación cualitativa sobre las prácticas y políticas curriculares relacionadas con la formación médica. El método adoptado fue el materialismo histórico dialéctico, en un estudio comparado de dos casos. La muestra fue intencional, con recorte en dos cursos de Medicina: el de la Pontificia Universidad Católica de Goiás (Brasil) y el de la Facultad de Ciencias de la Salud, de la Universidad de Beira do Interior (Portugal). El objetivo general era comparar las políticas curriculares para la enseñanza médica en los dos países y analizar las prácticas de organización curricular vigentes en las dos instituciones, teniendo en vista las políticas de cada país. Filosóficamente, la investigación se fundamentó en la teoría de la acción comunicativa de Habermas. Las aproximaciones entre los dos cursos perseveran en la matriz curricular con la enseñanza-aprendizaje centrada en el alumno y en el perfil del egresado. Los mayores distanciamientos se pusieron de manifiesto en la propuesta de inserción social, preconizada por la Pontificia Universidad Católica de Goiás, y en el presupuesto de la investigación e internacionalización de la Facultad de Ciencias de la Salud, de la Universidad de Beira do Interior. Se concluyó que hay necesidad de solidificación de los proyectos pedagógicos actuales y de adopción de una escuela reflexiva con propuestas reales, en el sentido de vislumbrar la posibilidad de transformaciones sociales en la realidad concreta.

Palabras clave educación médica; currículo; salud, políticas curriculares y acción comunicativa.

\section{Notas}

1 Pontifícia Universidade Católica de Goiás, Goiânia, Goiás, Brasil.

$<$ a.menezes.junior@uol.com.br>

Correspondência: Pontifícia Universidade Católica de Goiás, Departamento de Medicina, Avenida Universitária, n. 1.440, bloco K, Setor Universitário, CEP 74605-010, Goiânia, Goiás, Brasil.

2 Pontifícia Universidade Católica de Goiás, Goiânia, Goiás, Brasil.

<iriaucg@yahoo.com.br>

3 “This author analyzes the Bologna Process as an effort to harmonize Europe's higher education in the context of global competition. It includes original documents from intergovernmental and non-governmental organizations, up to the Bergen ministerial meeting of the Bologna Process in May 2005. The political decision to create a European higher education area aims to enhance mobility between European universities. The Bologna Process started with the 1999 Bologna Declaration. Now, there are regular ministerial meetings involving nearly all European countries, both EU and non-EU members. The book does not restrict itself to Europe only. It discusses developments in Asia and the Pacific and higher education policies by global organizations, such as Unesco, the World Bank (for the North-South divide), and the WTO, where some higher education services are covered by the General Agreement on Trade in Services."

4 Este artigo trata dos resultados da tese de doutoramento em Educação intitulada Ação comunicativa dialógica e as políticas curriculares na formação médica: aproximações e distanciamentos entre Brasil e Portugal, de Antônio da Silva Menezes Júnior, apresentada à PUC Goiás, financiada pela Fundação de Amparo à Pesquisa de Goiás. Não há qualquer conflito de interesse. 


\section{Referências}

APPLE, Michael W. Ideologia e currículo. 3. ed. Porto Alegre: Artmed, 2006.

BACHELARD, Gaston. A formação do espírito científico: contribuição para uma psicanálise do conhecimento. Rio de Janeiro: Contraponto, 2008.

BAUMAN, Zygmunt. O mal-estar da pós-modernidade. Rio de Janeiro: Jorge Zahar, 1998.

BRASIL. Lei de Diretrizes e Bases da Educação Nacional (LDB). Lei n. 9.394, de 20 de dezembro de 1996. Diário Oficial da União, Brasília, 23 de dezembro de 1996. Disponível em: <www.planalto.gov.br/CCIVIL_03/ leis/L9394.htm>. Acesso em: 21 ago. 2015.

BRASIL. Ministério da Educação. Conselho Nacional de Educação. Câmara de Educação Superior. Resolução CNE/CES n. 4, de 7 de novembro de 2001. Diário Oficial da União, Brasília, seção 1, p. 38, 9 nov. 2001.

CARVALHO, G. S. Encontro clínico no modelo biopsicossocial: autopercepção dos acadêmicos de Medicina da Pontifícia Universidade Católica de Goiás. 2010. 243 fls. Tese (Doutorado em Medicina) - Faculdade de Medicina, Universidade Federal de Goiás, Goiânia, 2010.

CUNHA, Maria I. A universidade: desafios políticos e epistemológicos. In: CUNHA, Maria I. (org.). Pedagogia universitária: energias emancipatórias em tempos neoliberais. Araraquara: Junqueira \& Marin, 2006. p. 13-29.

DATASUS. Cadastro Nacional de Estabelecimentos de Saúde. 2012. Disponível em: <www. cnes.datasus.gov.br/Mod_Ind_Unidade.asp? VEstado=52>. Acesso em: 5 jul. 2012.

EHRENSPERGER, Regina M. G. Políticas e práticas curriculares no ensino superior: Brasil/Portugal. 2009. 435 fls. Tese (Doutorado em Educação) - Instituto de Educação e Psicologia, Universidade do Minho, Braga, 2009.
FACULDADE DE CIÊNCIAS DA SAÚDE. Universidade da Beira do Interior. (FCS/UBI). Projeto de planejamento de curso de Medicina. Covilhã: FCS, 2008.

FREIRE, Paulo. Pedagogia do oprimido. 11. ed. Rio de Janeiro: Paz e Terra, 1999.

FREITAS, Luís C. Crítica da organização do trabalho pedagógico e da didática. Campinas: Papirus, 1995

FRIDMAN, Luís C. Postmodern vertigo (Giddens, Touraine, Bauman). Lua Nova, São Paulo, n. 47, p. 157-177, 1999.

GIDDENS, Anthony. Para além da esquerda e da direita. São Paulo: Editora Unesp, 1996.

HABERMAS, Jürgen. Théorie de l'agir communicationnel. Paris: Fayard, 1987. T. 1: Rationalité de l'agir et rationalisation de la société.

HABERMAS, Jürgen. A crise de legitimação do capitalismo tardio. Rio de Janeiro: Tempo Brasileiro, 2002.

HABERMAS, Jürgen. Verdade e progresso. São Paulo: Manole, 2007.

MACHADO, Joaquim P. Proposta de criação de um Curso de Medicina na Universidade do Minho. Braga: Universidade do Minho, 1991.

MACHADO, Joaquim P. Experiências inovadoras na aprendizagem no curso de Medicina. In: POUZADA, António S.; ALMEIDA, Leandro S.; VASCONCELOS, Rosa M. (ed.). Contextos e dinâmicas da vida acadêmica. Universidade do Minho: Guimarães, 2002. p. 25-32.

MANACORDA, Mario A. Marx e a pedagogia moderna. Campinas: Alínea, 2007.

MARX, Karl. Contribuição à crítica da economia política. 2. ed. São Paulo: Martins Fontes, 1983. 
PACHECO, José A. Currículo: teoria e práxis. Porto: Porto, 2001.

PONTIFÍCIA UNIVERSIDADE CATÓLICA DE GOIÁS (PUC Goiás). Curso de Medicina: projeto pedagógico - reformulação. Goiânia: PUC Goiás, 2011.

REINALDA, Bob. The Bologna Process Harmonizing Europe's Higher Education: Including the Essential Original Texts. Leverkusen: Barbara Brudich Publishers; 2006.

ROLDÃO, Maria C. Gestão curricular: fundamentos e práticas. Lisboa: Ministério da Educação, 1999
TOURAINE, Alain. Crítica da modernidade. Petrópolis - Rio de Janeiro: Vozes, 1994.

WEBER, Max. A ética protestante e o espírito do capitalismo. 4. ed. São Paulo: Livraria Pioneira Editora, 1986.

ZABALZA, Miguel A. O ensino universitário: seu cenário e seus protagonistas. Porto Alegre: Artmed, 2004.

Recebido em 04/06/2013

Aprovado em 05/08/2014 